\title{
Medical Cost to Treat Cervical Cancer Patients at a Social Security Third Level Oncology Hospital in Mexico City
}

\author{
Víctor Granados-García ${ }^{1 *}$, Patricia Piña-Sánchez ${ }^{2}$, Nancy Reynoso-Noveron ${ }^{3}$, \\ Yvonne N Flores ${ }^{4,5}$, Filiberto Toledano-Toledano ${ }^{6}$, Gloria Estrada-Gómez ${ }^{1}$, Teresa \\ Apresa-García $^{2}$, Arely A Briseño ${ }^{4}$
}

\begin{abstract}
Background: Cervical Cancer (CC) is an important public health problem worldwide. In 2015, CC was the sixth leading cause of death for women aged 30-59 years in Mexico. Despite the importance of having high-quality and accurate estimates of $\mathrm{CC}$ treatment costs that can be used to effectively evaluate the impact of preventive programs, there is scarce information on this topic in Mexico. Objective: To estimate the treatment costs by stage diagnosis in patients with CC at a Mexican Social Security Institute (IMSS) oncology hospital in Mexico City. Methods: An observational retrospective study of the resources used to treat 346 women with CC was conducted. Medical charts were reviewed and relevant resource use information was extracted using a data collection instrument that was created based on treatment guidelines. Data were classified into nine cost categories to estimate the total cost per patient. Results: The mean age of patients in the study sample was 54.3 years (range: 41-67), and the average body mass index (BMI) was $>26 \mathrm{~kg} / \mathrm{m}^{2}$. Among the participants, $37 \%$ were smokers, $39 \%$ had diabetes, and $56 \%$ had hypertension. The medical cost for stages I-IV ranged from $\$ 4,738$ to $\$ 6,058$ USD, with an estimated average cost of \$5,114 USD. Conclusion: Total treatment costs per patient are high, especially since they were estimated considering only 7.5 months of treatment. This is the first study to estimate the annual cost to treat $\mathrm{CC}$ in Mexico and to additionally document the resource pattern use, cost by stage of cancer, and the distribution by cost categories.
\end{abstract}

Keywords: Treatment costs- cost analysis- cervical cancer- Mexico

Asian Pac J Cancer Prev, 20 (5), 1547-1554

\section{Introduction}

Cervical cancer (CC) is a leading cause of morbidity and mortality. In 2012, this disease accounted for 528,000 new cases and 266,000 associated deaths worldwide (Ferlay et al., 2015), making it the fourth most common cancer among women (National Comprehensive Cancer Network, 2004). In Latin America and the Caribbean, the number of deaths due to this cancer are expected to increase $32 \%$ by 2030 (Executive Commitee (Panamerican Health Organization), 2017). In Mexico, CC is the sixth leading cause of death for women 30-59 years of age. The mortality rate was 9.2 and 11.9 per 100,000 women in 2012 and 2015, respectively (National Population Council (Mexico), 2016; National Institute of Geography and Information (Mexico), 2019).

Estimates of CC treatment costs are a fundamental component of the cost-effectiveness analyses of preventive programs that include human papillomavirus (HPV) vaccination and screening. Since these types of interventions are expected to reduce CC treatment costs and improve health, it is important to have accurate estimates of these costs (Tang et al., 2010). Having reliable population and country-specific cost estimates for the different stages of disease is also necessary because treatment costs vary considerably by stage at diagnosis (Tang et al., 2010). Additionally, it is helpful to know what assumptions were made and the specific values of the unitary costs that were used to estimate the cost of CC treatment in different settings. Despite the importance of having high-quality and accurate estimates of CC treatment costs that can be used to effectively evaluate the impact of preventive programs, there is scarce information on this topic in Mexico (Borja Aburto et al.,

${ }^{1}$ Epidemiological and Health Services Research Unit, Aging Area, Mexican Institute of Social Security (IMSS), ${ }^{2}$ Unit of Medical Research in Oncological Diseases, UMAE, Oncology Hospital, 21st Century National Medical Center, ${ }^{3}$ Research Directorate, National Institute of Cancerology, ${ }^{6}$ Evidence-Based Medicine Research Unit. Children's Hospital of Mexico Federico Gómez, National Institute of Health, Mexico City, ${ }^{4}$ Epidemiological and Health Services Research Unit, Morelos Delegation, IMSS, Cuernavaca Morelos, Mexico, ${ }^{5}$ UCLA Department of Health Policy and Management, Cancer Prevention and Control Research, Fielding School of Public, Health and Jonsson Comprehensive Cancer Center, Los Angeles, CA, USA. *For Correspondence: vic.granados@gmail.com 
2005; Sanchez-Roman et al., 2012)

A review of published studies available in PubMed and SCOPUS was conducted to identify articles that report the medical cost of CC treatment, written in English or Spanish, and published from 2000-2017. To evaluate the accuracy and comparability of the different cost analyses, the following five aspects of good practice were taken into account: 1) measurement of costs in precise and appropriate physical units; 2) the identification and justification of the sources of information on costs; 3 ) an adequate evaluation of costs; 4) a recognition and assessment of uncertainty in the analysis and conclusions; and 5) a comparison of the results to other studies, taking into account the methodology and generalizability of the findings, and offering possible explanations for any discrepancies. The search generated 15 articles that included seven from high-income countries (Canada, USA, Taiwan, United Kingdom and Italy) (Wolstenholme and Whynes, 1998; Ricciardi et al., 2009; Ferrandina et al., 2010; Subramanian et al., 2010; Tang et al., 2010; Cromwell et al., 2016; Pendrith et al., 2016) and eight manuscripts from middle- and low-income countries (Morocco, Ethiopia, Thailand, Mexico, China and Colombia) (Borja Aburto et al., 2005; Berraho et al., 2012; Sanchez-Roman et al., 2012; Shi et al., 2012; Termrungruanglert et al., 2012; Hailu and Mariam, 2013; Cheikh et al., 2016; Gamboa and Murillo, 2016). Most studies included an appropriate description of the sources of information that were used (e.g., administrative databases, chart review, interviews with medical and administrative staff, etc.). Although the sources of information were provided in the majority of the articles, there was no data on the quantity of goods and services consumed. In six of the published reports, a panel of experts estimated the quantity of medical goods and services used to treat a typical case of CC.

In most studies, the unitary prices used to generate cost estimates were obtained from the administrative personnel of local hospitals or by clinicians. In these cases, the authors did not make any adjustments to market prices when estimating costs. For example, a study of a public system in Taiwan relied on claims and payment information from the database of the national system of medical insurance (Tang et al., 2010). A report from Canada provided a detailed description of the different procedures and data sources used to estimate the costs to treat CC (Pendrith et al., 2016). Another study in Canada used the unitary prices established by different programs and systems to evaluate the costs of the British Columbia Cancer Agency (BCCA) (Cromwell et al., 2016).

A sensitivity analysis was used to assess uncertainty in most studies. The majority of researchers compared their own cost analyses to those found in other reports, focusing on the differences in methodology to evaluate the global costs per patient and the costs by stage of disease. Some authors compared their findings to other studies in terms of the different resources patterns used to treat $\mathrm{CC}$ and the differences in prices (Ferrandina et al., 2010; Subramanian et al., 2010; Tang et al., 2010). The most complete and clear comparisons were made between high-income countries (Ricciardi et al., 2009; Tang et al., 2010; Pendrith et al., 2016).
Our review of the literature revealed that in Mexico and other Latin America countries there is a lack of high-quality and accurate estimates of the cost to treat CC. Therefore, the objective of this study was to determine the cost to treat $346 \mathrm{CC}$ patients at a national reference oncology hospital at the $21^{\text {st }}$ Century Medical Center (OHMC21) in Mexico City. This hospital is part of the Mexican Institute of Social Security (IMSS), which is the largest health care provider and insurer in the country, offering health insurance to approximately 62 million people in 2015 (Mexican Institute of Social Security, 2016). IMSS has three levels of health care services: primary care (family medicine facilities), emergency room and hospitalization services (general hospitals), as well as the treatment of complex medical conditions, which include cancer (medical specialty hospitals). The OHMC21 is a medical specialty hospital that treats women in advanced stages of CC from all over the country.

\section{Materials and Methods}

A retrospective observational study was conducted to collect data on the use of resources to treat $\mathrm{CC}$ patients at the OHMC21. Published treatment guidelines were used to identify the costs of services and resources involved in the treatment of a patient with CC (General Health Council (Mexico), 2017). Costs were determined using information obtained from the patients' medical charts, which was reviewed and extracted using a data collection tool that was designed for this purpose. Treatment dates were defined based on the first and last appointments with a specialist that were registered in the patients' medical charts. A sample of medical charts was identified based on the list of CC patients and the date they received health care was established by consulting several sources. The patients' charts were also reviewed to identify all documentation (medical notes, tests orders, test results, inpatient and outpatient formats, nurse registries, etc.) that could provide information regarding the $\mathrm{CC}$ treatment they received from January 1, 2010 to December 31, 2014. After the required information was identified, a questionnaire was filled out for each patient, which was later entered into a database in Microsoft Access version 2010. The study protocol was approved by the IMSS National Committee of Scientific Research and the Ethics Committee.

A patient's medical chart was included only if it contained all the required information and met the following inclusion criteria: 1) a confirmed CC diagnosis during the study period, 2) an established period of treatment, and 3) a description of the $\mathrm{CC}$ treatment received (e.g., hysterectomy, radiotherapy, brachytherapy and chemotherapy, or some other treatment). The exclusion criteria were: 1) medical indications that the patient should not receive CC treatment, 2) death of the patient or discontinuing treatment, and 3) missing or incomplete information regarding a confirmed CC diagnosis, the treatment received, or the total number of sessions of radiotherapy or brachytherapy.

To estimate the total cost per patient, data were classified into the following nine categories: 1 ) resonance 
imaging and lab testing, 2) consultations with oncologists and other medical specialists 3 ) radiotherapy and brachytherapy, 4) chemotherapy, 5) pathology, 6) surgery, 7) hospitalization and emergency room visits, 8) transfusions, and 9) complications. Information regarding the types and amounts of supplies and services associated with these procedures was obtained and used to estimate the total cost per patient for a base case scenario. Costs were calculated by multiplying the number of supplies or services provided by their unitary prices. The average costs per patient and by stage of cancer as well as the corresponding standard deviations, percentiles, and 95\% confidence intervals were estimated. Costs are reported in US dollars (USD) using the average official exchange rate for December of 2017 (19.18 pesos per 1 USD) of the National Bank of Mexico (BANXICO), which was used to convert Mexican pesos to USD. We also updated the pesos from 2016 to December 2017 using the official national consumer price index from the National Institute of Geography and Information. A deterministic sensitivity analysis was conducted to examine the extent to which the modification of unitary prices of radiotherapy sessions and specialty consultations change the overall average cost per patient and cost by stage of CC.

Costs were estimated from the health care provider's point of view, which only takes into account the direct costs of medical treatment. Costs were determined based on prices from the official list of IMSS unitary prices of health services (Official Newspaper for New Legislation (Mexico), 2016). The cost of other supplies and services that were not included on the IMSS price list were determined using market prices. All analyses were carried out using Microsoft Excel 2010 and Stata version 12.

\section{Results}

We identified 575 patients with $\mathrm{CC}$ who were treated at the OHMC21 during a five-year period from 2010-2014. Of these cases, 229 were excluded because their medical charts were unavailable or had insufficient treatment information, or their chart listed another diagnosis. A total of 346 charts $(60 \%)$ were reviewed to determine the resources used for the medical treatment of CC (Table 1). The mean age of the CC patients included in this study was 54.3 years (range 41-67 years). Most of the women did not complete high school (77\%) and more than half were not formally employed (57\%). Two thirds of the women had IMSS insurance through a relative or their pension, while $32 \%$ were covered by IMSS through their employment. The average BMI was $26.2 \mathrm{~kg} / \mathrm{m}^{2}, 37 \%$ were current smokers, 39\% were diabetic, and 56\% had hypertension (Table 1).

Resource utilization results suggest a frequent use of specialty consultations (Table 2). The vast majority of women received radiotherapy (89\%), with an average of 24 sessions (CI 95\%, 21.44-26.73). Brachytherapy was provided to $71 \%$ and chemotherapy to $50 \%$ of the women, the latter with an average of 4.8 sessions. Women who had surgery made up $32 \%$ of the sample. A total of 322 women had one or more biopsies taken and the average number of biopsies per patient was 2.69. The percentage of women
Table 1. Demographic, Socioeconomic, and Health Characteristics of Patients at the IMSS Oncology Hospital $(\mathrm{n}=346)$

\begin{tabular}{|c|c|c|}
\hline \multirow{2}{*}{$\begin{array}{l}\text { Variable } \\
\text { Age (years, mean) }\end{array}$} & \multicolumn{2}{|c|}{ Frequency* (\%) } \\
\hline & 54.3 & $( \pm 12.9)^{\ddagger}$ \\
\hline \multicolumn{3}{|l|}{ Education } \\
\hline None & 15 & $9 \%$ \\
\hline Primary & 82 & $48 \%$ \\
\hline Secondary & 35 & $20 \%$ \\
\hline Preparatory & 27 & $16 \%$ \\
\hline University & 12 & $7 \%$ \\
\hline \multicolumn{3}{|l|}{ Employment } \\
\hline Not employed & 106 & $57 \%$ \\
\hline Retired & 34 & $18 \%$ \\
\hline Other activity & 47 & $25 \%$ \\
\hline \multicolumn{3}{|l|}{ Insurance status } \\
\hline Worker & 108 & $32 \%$ \\
\hline Beneficiary & 164 & $48 \%$ \\
\hline Pensioner & 70 & $20 \%$ \\
\hline Weight (Kg, mean) & 61.4 & $( \pm 13.2)^{¥}$ \\
\hline BMI $\left(\mathrm{kg} / \mathrm{m}^{2}\right)$ & 26.2 & $( \pm 5.2)^{¥}$ \\
\hline \multicolumn{3}{|l|}{ Current smoker } \\
\hline No & 174 & $63 \%$ \\
\hline Yes & 100 & $37 \%$ \\
\hline \multicolumn{3}{|l|}{ Diabetes } \\
\hline No & 123 & $61 \%$ \\
\hline Yes & 80 & $39 \%$ \\
\hline \multicolumn{3}{|l|}{ Hypertension } \\
\hline No & 100 & $44 \%$ \\
\hline Yes & 125 & $56 \%$ \\
\hline
\end{tabular}

who received a CAT (computerized axial tomography) or colposcopy were $27 \%$ and $37 \%$, respectively. A cytological study was conducted on 122 women. The number of women undergoing hospitalization, blood transfusion, and complications accounted for 20\%, 22\% and $8 \%$ of the sample, respectively.

The $\mathrm{CC}$ treatment costs for stages I-IV range from USD $\$ 4,800$ (CI95\%: \$4,364-\$5,236) to USD \$5,398 (CI95\%: \$4,615-\$6,180), which correspond to different durations in treatment (Table 3). However, the differences in costs by stage are not statistically significant ( $\mathrm{p}$-value $>0.001)$, nor is the difference in cost between the unclassified group and stage I.

Figure 1 indicates that the radiotherapy and brachytherapy (29\%) procedures represent the greatest cost of CC treatment, followed by consults with oncologists and other medical specialists (23\%) and surgery (15\%). These three categories account for $67 \%$ of the total treatment costs in this sample of CC patients. Of the remaining procedures the most notable are chemotherapy (13\%) followed by hospitalization (10\%).

The sensitivity analysis results show that total average cost per patient increases from USD \$5,411 (in the base 
Table 2. Resource Utilization of CC Patients at an IMSS Oncology Hospital ( $n=346)$

\begin{tabular}{|c|c|c|}
\hline Costs Category (Number of patients who used the service) & Average units consumed per patient ${ }^{*}(\mathrm{IC} 95 \%)$ & Unitary Price $^{\dagger}$ \\
\hline \multicolumn{3}{|l|}{ 1.Diagnostic } \\
\hline \multicolumn{3}{|l|}{ Images tests } \\
\hline Computerized axial tomography $(\mathrm{n}=199)$ & $1.66(1.43-1.89)$ & 157 \\
\hline $\mathrm{X}$ ray $(\mathrm{n}=73)$ & $1.14(0.88-1.40)$ & 34 \\
\hline Ultrasound $(\mathrm{n}=84)$ & $1.23(0.96-1.49)$ & 34 \\
\hline Rectosigmoidoscopy ( $\mathrm{n}=63$ ) & $1.1(0.82-1.37)$ & 58 \\
\hline Colposcopy (n=127) & $1.18(0.98-1.39)$ & 58 \\
\hline Cystoscopy (n=96) & $1.36(1.09-1.64)$ & 58 \\
\hline \multicolumn{3}{|l|}{ Laboratory tests } \\
\hline Clinical chemistry $(n=279)$ & $2.76(2.44-3.09)$ & 9 \\
\hline Hematology $(n=265)$ & $2.58(2.27-2.89)$ & 9 \\
\hline Urine culture $(\mathrm{n}=177)$ & $1.86(1.58-2.13)$ & 9 \\
\hline \multicolumn{3}{|l|}{ 2.Consultations } \\
\hline Specialty consultations $(n=346)$ & $12.04(10.77-13.31)$ & 96 \\
\hline Pain clinic and palliative consultations $(\mathrm{n}=8)$ & $4(1.23-6.77)$ & 96 \\
\hline \multicolumn{3}{|l|}{ 3.Radioterapy and brachytherapy } \\
\hline Radiotherapy (n=319) & $24.08(21.44-26.73)$ & 60 \\
\hline brachytherapy (n=247) & $3.7(3.24-4.16)$ & 60 \\
\hline \multicolumn{3}{|l|}{ 4.Chemoteraphy } \\
\hline Chemotherapy $(\mathrm{n}=176)$ & $4.82(4.11-5.53)$ & 263 \\
\hline \multicolumn{3}{|l|}{ 5. Anatomic pathology } \\
\hline Biopsy $(\mathrm{n}=322)$ & $2.69(2.40-2.98)$ & 14 \\
\hline Cytology $(\mathrm{n}=122)$ & $1.29(1.06-1.52)$ & 14 \\
\hline \multicolumn{3}{|l|}{ 6.Surgery } \\
\hline Hysterectomy piver I $(\mathrm{n}=69)$ & 1(na) & 1,836 \\
\hline Hysterectomy piver II ( $\mathrm{n}=11)$ & 1(na) & 1,836 \\
\hline Hysterectomy piver III(n=30) & 1(na) & 1,836 \\
\hline \multicolumn{3}{|l|}{ 7.Hospitalizations } \\
\hline Days of hospitalization $(\mathrm{n}=69)$ & $6.28(4.79-7.76)$ & 386 \\
\hline Emergency room visit $(\mathrm{n}=10)$ & $1.1(0.42-1.78)$ & 147 \\
\hline Intensive therapy $(\mathrm{n}=1)$ & 4(na) & 1,894 \\
\hline 8.Transfusion $(\mathrm{n}=78)$ & $3.56(2.77-4.36)$ & 33 \\
\hline 9.Complications $(\mathrm{n}=20)$ & 1 (na) & Range of prices \\
\hline
\end{tabular}

${ }^{¥}$ Average amount of services and tests for CC patients during the 7.56 months of follow up. " Here we present only those laboratory and image tests most frequently used in the treatment of patients; ${ }^{\dagger}$ Source, Official newspaper for new legislation with official prices for IMSS health services; Unitary costs in USD 2017. Unitary costs for items like mastography, bone scan, renal scan and urography are not included in this source. If official IMSS prices for these items were not available, we used market prices.

Table 3. Costs by Stage of Disease in CC Patients at an IMSS Oncology Hospital ( $\mathrm{n}=346)$

\begin{tabular}{lcc}
\hline Stage $(\mathrm{n})$ & (Follow up time in months) & Average costs by stage ${ }^{¥ \neq}(\mathrm{CI} 95 \%)$ \\
\hline I (47) & 8.38 & $5,398(4,615-6,180)$ \\
II (114) & 8.85 & $4,800(4,364-5,236)$ \\
III (112) & 6.38 & $4,943(4,290-5,597)$ \\
IV (29) & 5.93 & $5,386(4,246-6,525)$ \\
Without stage (38) & 7.98 & $6,058(5,329-6,787)$ \\
Without information (6) & 3.49 & $4,738(3,568-5,909)$ \\
Total (346) & 7.56 & $5,114(4,808-5,419)$ \\
\hline
\end{tabular}

${ }^{¥}$ Costs by stage include the following: specialty consultations, laboratory tests, image tests, specialty consultations, radiotherapy, chemotherapy, hospitalization, surgery, transfusion and anatomic pathology. ‡ Costs are in USD of 2017. 


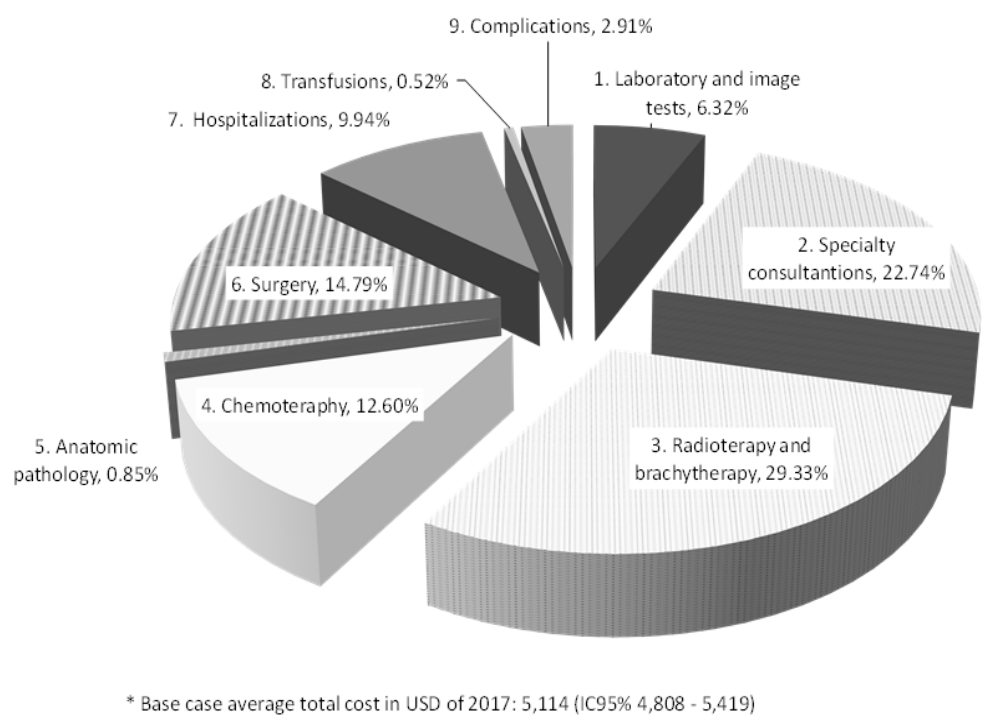

Figure 1. Contribution of Nine Cost Categories to Average Cost per Patient.

case scenario) to USD \$6,866 (35\%) and USD \$11,466 (124\%) when the cost of a radiotherapy session increases from USD \$60 to \$132 (1.2 times more) and USD \$316 (4.3 times more), respectively (Figure 2). In terms of the total cost per patient and stage, stage II has the largest increase when the cost of radiotherapy session rises, from a base case cost of USD $\$ 4,800$ to USD $\$ 11,845$ (147\% more). The next stage with an significant increase is stage III, with an increase of $131 \%$ in the average cost per patient.

Changes in the average cost due to variations in the cost of specialty consults were less evident. A reduction from USD \$96 to USD \$66 (-31\%) or USD \$33 (-65\%) in the price of a specialty consult had an impact on the average cost per patient of $7 \%$ and $15 \%$, respectively. The largest difference in total average costs are observed between stages II and III.

\section{Discussion}

The purpose of this study was to estimate the average cost of CC treatment per patient and the pattern of resource use to treat these patients. These two elements are critically important in order to accurately estimate the total cost to treat patients with CC at the IMSS Oncology Hospital. The pattern of consumption is characterized by the use, in a relatively short period (7.56 months), of a large quantity of resources. The largest consumption

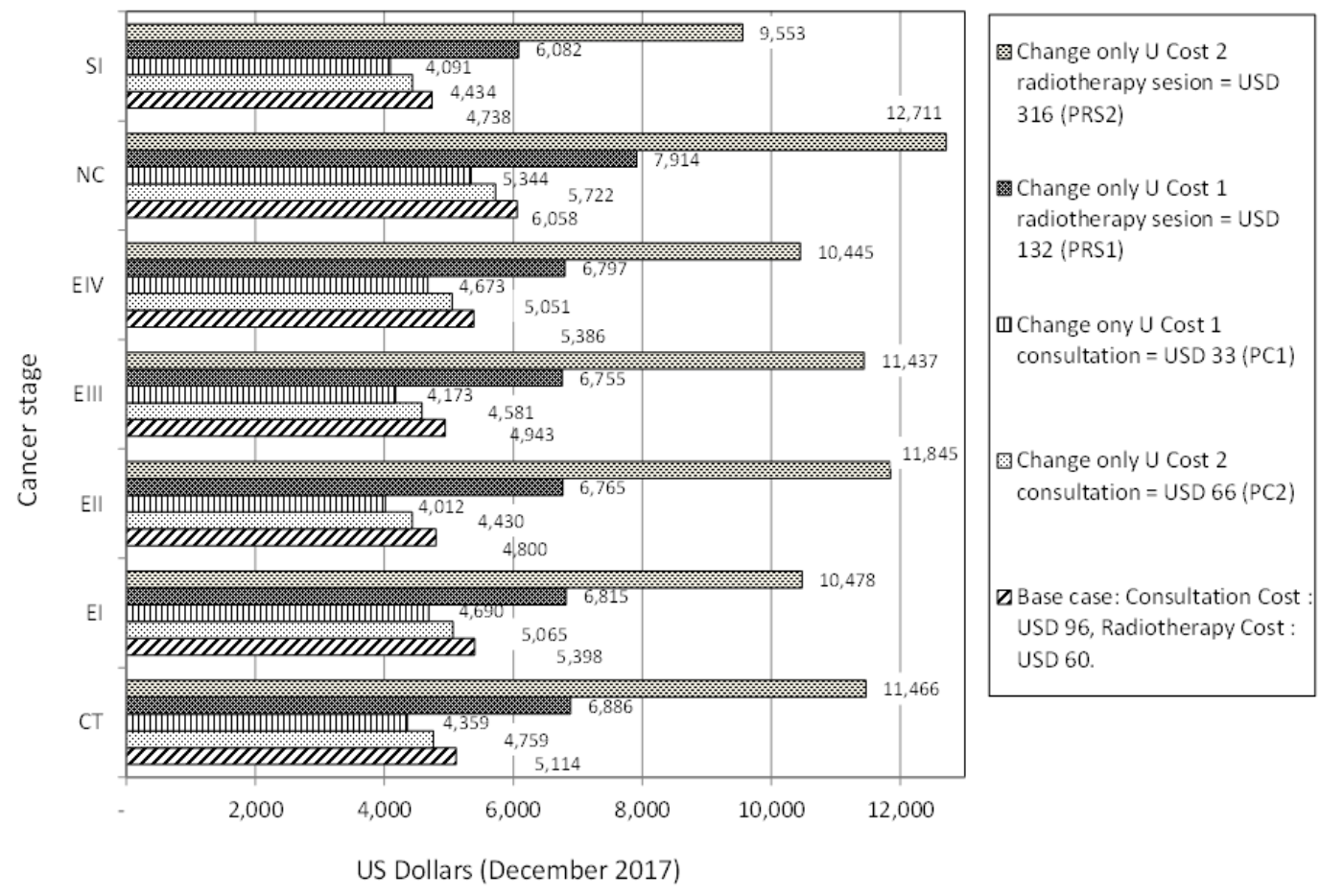

Figure 2. Sensitivity Analysis. Variations in cost per patient by stage using different unitary prices of consultations and radiotherapy. 
observed is in specialty consultations, radiotherapy and brachytherapy sessions, and biopsies. Resource use is less intensive in chemotherapy, surgery, hospitalization, transfusion and diagnostic tests (CAT and colposcopies). The estimated total average cost of $\mathrm{CC}$ treatment during the follow up time between the first and last consultation was USD \$ 5,114 (CI95\%: \$4,808-\$5,419). The largest number of patients receiving treatment are in stage III and II, but the most expensive is stage IV. However, cost differences between stages are not statistically significant. The sensitivity analyses explored the uncertainty of prices by using the cost of similar services offered by private providers for two of the most important costs: radiotherapy and specialist consultation. Our findings indicate significant changes in the average costs per patient in the extremes of price modifications. When we reduce the cost of consultation by $65 \%$ (from USD $\$ 96$ to $\$ 30$ ) the total average cost drops by $20 \%$, and when we increase the cost of one radiotherapy session by 4.3 times (from USD $\$ 60$ to $\$ 316$ ) the overall average cost increases by $111 \%$.

Our results differ from those of other publications that also report cost analyses (Borja Aburto et al., 2005; Sanchez-Roman et al., 2012). A study that examined a sample of women with CC at the same IMSS oncology hospital (OHMC21), found that the direct medical cost per year of CC treatment was USD \$4,404 (Sanchez-Roman et al., 2012). One of the main differences between our studies is the pattern of use of radiotherapy and chemotherapy services. The previous study examined a sample of 80 patients with $\mathrm{CC}$, and reported an average of 13.54 radiotherapy sessions and 0.86 chemotherapy sessions, per year of treatment (Sanchez-Roman et al., 2012). In our study, we observed an average of 23.27 radiotherapy sessions in a group of 319 patients, and six chemotherapy sessions in a group of 176 women, both during the 7.69 months of treatment. Assuming similar standard deviations, the patterns of resource use are significantly different in the two studies. This could be explained by the differing sample sizes of the studies, but also due to the possible inclusion of medical charts with incomplete information, and a lack of medical record information in the study conducted by Sanchez-Roman et al., (2012).

Another study found that the average cost to treat the four stages of CC during a one year period was USD $\$ 6,732$ (Borja Aburto et al., 2005), which is higher than our estimated average cost of $\$ 5,114$ USD (CI95\%: $\$ 4,808-\$ 5,419)$. This difference is likely due to the different methods used to determine resource use or prices in our studies. Nevertheless, this is somewhat speculative since the aforementioned study did not report the resource data they used to calculate their cost estimates.

There is no consensus about which is more precise, a cost analysis based on the review of medical charts or on the opinions of experts in their field. Most of the articles that use the latter method fail to provide an adequate explanation of their methods (Borja Aburto et al., 2005; Ricciardi et al., 2009; Shi et al., 2012; Gamboa and Murillo, 2016), which can sometimes cast into doubt the reliability of using a panel of experts to generate cost estimates. Moreover, this methodology only describes the resource use pattern of one or a few cases, and probably does not reflect the ranging variability of CC cases (e.g. the distinct possibilities of case mix and degrees of disease severity). Thus, using a panel of experts to estimate costs has several limitations in terms of its ability to reliably capture the resources consumed by CC patients.

The 15 reports that were examined as part of our literature review describe a variety of methodologies used to estimate the cost to treat CC. In high-income countries, analyses were mainly conducted using statistical models that were constructed with cost information from administrative and epidemiological databases (Wolstenholme and Whynes, 1998; Ferrandina et al., 2010; Subramanian et al., 2010; Tang et al., 2010; Cromwell et al., 2016; Pendrith et al., 2016). The advantage of this approach is that data are collected in a systematic and consistent way. Contrarily, in middle- and low-income countries, the cost analyses are more frequently carried out through the review of medical records, information provided by a panel of experts, a treatment algorithm, or micro-costing techniques (Sanchez-Roman et al., 2012; Shi et al., 2012; Hailu and Mariam, 2013; Gamboa and Murillo, 2016). However, these methods may result in greater errors that lead to incorrect cost estimates. An advantage of cost analyses that rely on administrative and epidemiological databases is that the information generated on the use of resources at the patient level, does not require a certain set of conditions nor resources for the design, collection, and management of the data.

Another relevant issue in estimating the costs of treatment is the extent to which unitary prices depict the actual economic costs of resources. Some experts have recommended using market prices for cost analyses (Drummond et al., 2005). The 15 reports identified in the literature review mostly used prices provided by clinicians or hospital administrators who have access to financial information. In many of the studies, the researchers did not make any adjustments to account for market prices when estimating costs (Tang et al., 2010; Sanchez-Roman et al., 2012; Shi et al., 2012; Hailu and Mariam, 2013; Cromwell et al., 2016; Gamboa and Murillo, 2016; Pendrith et al., 2016). For the present study, we used prices from the official administrative list of unitary costs at IMSS. Since most studies at IMSS have employed this methodology to estimate costs, an advantage exists regarding the availability and comparability of data. However, since the methodology used to establish the unitary costs that are included in the official administrative IMSS pricing list is not available, it is impossible to determine whether those prices reflect actual production costs. The prices from the official IMSS list may over or underestimate prices, which would result in an over or underestimate of the actual cost of CC treatment at the IMSS OHMC21. Additionally, this could generate uncertainty in resource allocation at the hospital, which represents a limitation of our study.

An additional limitation is that the beginning and end of treatment dates were not recorded prospectively; this would guarantee a greater accuracy of information. The strategy we used to approximate the dates was to record the date of the first consultation in the period observed (2010 to 2014). We consider that this provides an accurate estimate of the period of treatment. A potential limitation 
is the magnitude of bias due to the underestimate of the quantity of supplies and services that were actually used by each patient who received CC treatment. The extent to which the data in the medical records accurately describes the resources consumed by a given patient is unknown. A methodology to estimate such a gap could help reduce the uncertainty of the cost analysis. One possibility is to determine the quantity of supplies and medical services designated to women who are undergoing $\mathrm{CC}$ treatment in a prospective follow up study, and then compare the results to the information reported in their medical records. Despite these limitations, we consider that our sample size provides a reasonably accurate depiction of the resource use pattern for the treatment of CC at IMSS. The disadvantage of a prospective follow up of patients during treatment is the considerable resources required to carry out the logistics of record keeping and documentation.

In conclusion, costs associated with $\mathrm{CC}$ treatment represent a significant amount of resources spent by a large health care organization, such as IMSS. An estimate of this amount can be calculated by considering that $15,549 \mathrm{CC}$ patients were treated at IMSS hospitals in 2015 (Mexican Institute of Social Security, 2016). The total annual amount of resources used to treat these patients with our average per patient costs estimates represent USD \$79.5 million. This estimate could be underestimated since the present study only considered resources used over 7.56 months of treatment. Based on these findings, our recommendation is to estimate the production costs of services on a regular basis in order to manage the balance between resources needed to provide high-quality services and the added value of offering these services to patients insured by IMSS.

\section{Aknowledgments}

This research was funded by the Health Research Fund of Mexican Institute of Social Security (Grant number: FIS/IMSS/PROT/MD15/1507) awarded to VGG. Funding was used for collection and coding of data. Funding was not provided for writing the present manuscript.

The project was authorized by the IMSS National Comision of Scientific Research and the biosecurity and ethical commites with authorization number: R-2012-785-044. The project did not requir informed consent because the main source of information was informed review of medical charts (with standards of confidentiality), and published manuscripts. The Researchers in not interview patients, manipulate biological materials nor provide treatment to patitents during the course of study.

We want to thank the authorities of the Oncology Hospital at the $21^{\text {st }}$ Century Medical Center (OHMC21) in Mexico City, especially the Medical Informatics and clinical registry (ARIMAC) for providing us the charts to review.

Dr. Patricia Piña Sánchez is currently a fellow from "Fundación IMSS A.C."

The funders had no role in the study design, data collection and analysis, decision to publish, or preparation of this manuscript.
Authors declare that they do not have any conflicts of interest.

\section{References}

Berraho M, Najdi A, Mathoulin-Pelissier S, et al (2012). Direct costs of cervical cancer management in Morocco. Asian Pac $J$ Cancer Prev, 13, 3159-63.

Borja Aburto V, Aguilar-Madrid G, Carlos Rivera F, et al (2005). Costs of health care of diseases with high mortality in IMSS insured workers. In 'Las múltiples facetas de la investigación en salud 4.', Eds Instituto Mexicano del Seguro Social., México, D.F.

Cromwell I, Ferreira Z, Smith L, et al (2016). Cost and resource utilization in cervical cancer management: a real-world retrospective cost analysis. Curr Oncol Rep, 23, 14-22.

Cheikh A, El Majjaoui S, Ismaili N, et al (2016). Evaluation of the cost of cervical cancer at the National Institute of Oncology, Rabat. Pan Afr Med J, 23, 209.

Drummond M, Sculpher M, Torrance G, et al (2005). Chapter 3. Critical assessment of economic evaluation. In 'Methods for the Economic Evaluation of Health Care Programmes', Eds Oxford University Press, Oxford.

Ferlay J, Soerjomataram I, Dikshit R, et al (2015). Cancer incidence and mortality worldwide: sources, methods and major patterns in GLOBOCAN 2012. Int J Cancer, 136, 359-86.

Ferrandina G, Marcellusi A, Mennini FS, et al (2010). Hospital costs incurred by the Italian National Health Service for invasive cervical cancer. Gynecol Oncol, 119, 243-9.

Gamboa O, Murillo R (2016). Estimation of economic burden of pre-neoplasic lesions and cervical cancer in Colombia. Implications for HPV vaccination. Revista Colombiana de Cancerología, 20, 61-72.

General Health Council (MEXICO). (2017). Diagnostic and treatment of cervical cancer. Evidence and recomendations [Online]. Ciudad de Mexico. Mexico: Secretaria de salud. Available: http://www.cenetec-difusion.com/CMGPC/ IMSS-333-09/ER.pdf.

Hailu A, Mariam DH (2013). Patient side cost and its predictors for cervical cancer in Ethiopia: a cross sectional hospital based study. BMC Cancer, 13, 69.

Mexican Institute of Social Security. 2016. Report to Federal Excecutive and Congress of the Financial Situation and Risks of IMSS 2015-2016 [Online]. IMSS. Available: http://www. imss.gob.mx/conoce-al-imss/informe-2015-2016.

National Comprehensive Cancer Network (2004). Cervical cancer clinical practice guidelines in oncology. J Natl Compr Cancer Netw, 2, 612.

National Institute of Geography and Information (Mexico) (2019). [Men and women information by state from 1990 to 2015] [Online]. INEGI. Available: https://www.inegi. org.mx/app/tabulados/pxweb/inicio.html?rxid=d518b312a32e-4d23-a8dd-08a64c187a6c\&db=Poblacion \&px=pob lacion_02.

National Population Council (Mexico) (2016). Projections of population from Mexico and federal states, 2016-2050 [Online]. CONAPO. Available: https://datos.gob.mx/busca/ dataset/proyecciones-de-la-poblacion-de-mexico-y-de-lasentidades-federativas-2016-2050 [Accessed 04 April 2019].

Official newspaper for new legislation (Mexico) (2016). Unitary costs by health care level for 2016 (IMSS) [Online]. Ciudad de México. Mexico: Secretary of Goverment. Available: http://dof.gob.mx/nota_detalle.php?codigo $=5427055 \& \mathrm{fec}$ ha $=25 / 02 / 2016$.

Pendrith C, Thind A, Zaric GS, Sarma S (2016). Costs of cervical cancer treatment: population-based estimates from Ontario. 
Curr Oncol, 23, e109-15.

Ricciardi A, Largeron N, Giorgi Rossi P, et al (2009). Incidence of invasive cervical cancer and direct costs associated with its management in Italy. Tumori, 95, 146-52.

Sanchez-Roman FR, de Jesus Carlos-Rivera F, Guzman-Caniupan JA, et al (2012). Estimation of health-care costs for cervical uterine neoplasm. Rev Med Inst Mex Seguro Soc, 50, 99-106.

Shi JF, Chen JF, Canfell K, et al (2012). Estimation of the costs of cervical cancer screening, diagnosis and treatment in rural Shanxi Province, China: a micro-costing study. $B M C$ Health Serv Res, 12, 123.

Subramanian S, Trogdon J, Ekwueme DU, et al (2010). Cost of cervical cancer treatment: implications for providing coverage to low-income women under the Medicaid expansion for cancer care. Womens Health Issues, 20, 400-5.

Tang CH, Pwu RF, Tsai IC, et al (2010). Costs of cervical cancer and precancerous lesions treatment in a publicly financed health care system. Arch Gynecol Obstet, 281, 683-95.

Termrungruanglert W, Havanond P, Khemapech N, et al (2012). Model for predicting the burden and cost of treatment in cervical cancer and HPV-related diseases in Thailand. Eur J Gynaecol Oncol, 33, 391-4.

Wolstenholme JL, Whynes DK (1998). Stage-specific treatment costs for cervical cancer in the United Kingdom. Eur $J$ Cancer, 34, 1889-93.

\section{๑๐ब}

This work is licensed under a Creative Commons AttributionNon Commercial 4.0 International License. 